serum from BD patients using GC/TOF-MS. Further studies including a larger number of patients with $B D$ would be warranted to validate the metabolite profiles for clinical use and to ascertain the feasibility of metabolomic analysis in BD.

Disclosure of Interest: None declared

DOI: 10.1136/annrheumdis-2017-eular.3104

\section{FRI0332 DIFFERENCES BETWEEN TEMPORAL ARTERY BIOPSY-POSITIVE AND BIOPSY-NEGATIVE GIANT CELL ARTERITIS: A COMPARATIVE COHORT STUDY}

K. Yeruva, K.J. Warrington, C.S. Crowson, M.J. Koster. Rheumatology, Mayo Clinic, Rochester, United States

Background: Giant cell arteritis (GCA) is the most common systemic vasculitis in patients aged 50 years or older. The presence of cranial features and an abnormal temporal artery biopsy have historically been the primary focus for diagnosis of this condition. A notable percentage of patients with symptoms of GCA have negative temporal artery biopsies, however, few cohort studies exist comparing the presentation and outcome of patients based on temporal artery positivity. Objectives: To establish a large, single institution cohort of patients with temporal artery biopsy-negative GCA. To identify differences in presentation and outcome among patients with temporal artery biopsy-negative and temporal artery biopsy-positive GCA.

Methods: Patients with temporal artery biopsy-negative GCA diagnosed between $1 / 1 / 1998$ and 12/31/2013 were identified retrospectively. Final diagnosis was confirmed by consensus among two rheumatologists and a physician abstractor. Baseline characteristics and outcomes were compared to a previously established biopsy-positive GCA cohort $(n=286)$ from the same institution.

Results: 110 patients with temporal artery biopsy-negative GCA were identified. Unilateral biopsies were performed in 73 , bilateral-sequential in 10 , and bilateral same day in 27 cases. Median duration between steroid initiation and biopsy was 3 days. Median length of first biopsy was $14 \mathrm{~mm}$ and second biopsy (if performed) was $22 \mathrm{~mm}$. Among biopsy-negative patients with advanced imaging within 6-months of diagnosis, $67 \%(41 / 61)$ had evidence of large vessel vasculitis. Patients with biopsy-negative GCA were younger $(72.0 \pm 9.0$ vs $75.0 \pm 7.6 ; p=0.001)$, met fewer ACR criteria ( $\geq 3$ criteria $64 \%$ vs $95 \% ; p<0.001$ ) and had a shorter time from symptom onset to diagnosis (median 1.1 vs 2.1 months; $p<0.001$ ). Vascular risk factors evaluated at diagnosis showed a higher rate of pre-existing hypertension and obesity among patient with biopsy-negative GCA but similar rates of smoking and diabetes mellitus. Frequency of headache and vision loss at time of presentation were similar between groups. However, biopsy-negative GCA patients had more temporal artery tenderness ( $35 \%$ vs $16 \% ; p<0.001)$ and arm claudication $(13 \%$ vs $2 \% ; p<0.001)$ but less frequent jaw claudication $(19 \%$ vs $52 \% ; p<0.001$ ). Anorexia, fatique, and arthralgia were also more commonly noted in biopsy-negative patients. Baseline CRP was lower among patients with negative biopsies ( $44.3 \pm 53.6$ vs $70.4 \pm 63.9 \mathrm{mg} / \mathrm{L} ; \mathrm{p}<0.001)$.

Initial prednisone dose was similar among both cohorts. Although cumulative glucocorticoid (GC) was lower in biopsy-negative patients at 1 year $(6.3 \pm 2.6$ vs $7.2 \pm 2.7 \mathrm{~g} ; \mathrm{p}=0.004)$, cumulative GC doses at 2-years and 5 -years were equivalent. Biopsy-positive patients (5-years, $56 \pm 3 \%$ ) were able to discontinue GC sooner than biopsy-negative patients (5-years, $30 \pm 5 \% ; p<0.001$ ). The number of relapses, time-to-first relapse, annual relapse rate and mortality did not differ based on biopsy positivity.

Conclusions: While similarities are present, notable differences are observed at diagnosis in patients with biopsy-negative GCA. Further research is needed to confirm and understand the variability in GC duration.

Disclosure of Interest: None declared

DOI: 10.1136/annrheumdis-2017-eular.1936

\section{FRI0333 OCULAR INVOLVEMENT IN BEHÇET'S DISEASE ABOUT 221 CASES}

K. Echchilali, W. Bouissar, M. Moudatir, F.-Z. Alaoui, H. Elkabli. Internal Medicine Department, University Hospital Centre Ibn Rochd, Casablanca, Morocco

Background: Behçet's disease (BD) is a chronic systemic inflammatory disorder of unknown etiology. It's chracterised by recurrent oral aphtosis and genital ulcer. Ocular involvement has been recognized since the time of Hypocrates. Estamates of the prevalence vary in different countries and may represent differences in the disease, in acces to health care and in availabale treatments.

Objectives: The aim of this study is to describe the epidemiological and clinical characteristics in moroccan patients with ocular BD.

Methods: retrospective study in internal medicine department over 13 years and including 221 patients with ocular BD. The diagnosis was performed by the International Study Group for Behçet's Disease and/or the International Criteria for Behçet's Disease.

Results: 221 (prevalence: 43\%) had ocular involvement.154 men and 63 women (sex ratio: 2.5). The mean age at the onset of ocular involvement was 30.5 years. This achievement was inaugural in $18.55 \%$ of cases. The average time of diagnosis in other cases was 3.41 years. There was a high prevalence of Uveitis (total: $34 \%$, anterior: $32 \%$, posterior: 31.2 ). Retinal Vasculitis was noted in 37 eyes and retinal detachment in 17 eyes. Neurological events were associated in $13.57 \%$ of cases, joint and vascular events in respectively 18 and 17 cases.
The topical corticosteroid therapy was prescribed in $27,14 \%$ of cases, oral in 47 , $51 \%$ and bolus in $29,41 \% .47,51 \%$ of casers received Cyclophosphamide and $19 \%$ received Azathioprine. Cyclosporine was administered in 3 cases, interferon and Infkiximab in 2 cases each. The evolution was good in 111 cases $(50.22 \%)$, treatment failure was noted in $24 \%$ of cases and recidivism in $16.74 \%$ of cases.63 patients have evolved into blindness which was bilateral in $51.1 \%$ of cases.

Conclusions: Only early diagnosis and appropriate management can improve the prognosis of ocular involvement in BD.

Disclosure of Interest: None declared

DOI: 10.1136/annrheumdis-2017-eular.5961

\section{FRI0334 WHAT IS THE ABSOLUTE RISK OF DEVELOPING DIABETES MELLITUS IN PATIENTS WITH GLUCOCORTICOID-TREATED POLYMYALGIA RHEUMATICA AND GIANT CELL ARTERITIS? A SYSTEMATIC REVIEW AND META-ANALYSIS}

L. Lai ${ }^{1}$, E. Harris ${ }^{1,2}$, R.M. West ${ }^{3}$, S.L. Mackie ${ }^{1,4} \cdot{ }^{1}$ Leeds Institute for Rheumatic and Musculoskeletal Medicine, University of Leeds; ${ }^{2}$ School of Human and Health Sciences, University of Huddersfield; ${ }^{3}$ Leeds Institute of Health Sciences, University of Leeds; ${ }^{4}$ NIHR-Leeds Musculoskeletal Biomedical Research Unit, Leeds, United Kingdom

Background: Polymyalgia rheumatica (PMR) and giant cell arteritis (GCA) are treated with glucocorticoids (GCs) but long-term GC use is associated with diabetes mellitus (DM). The absolute incidence of this serious complication in this patient group remains unclear.

Objectives: To quantify the absolute risk of GC-induced DM in PMR and GCA in published literature.

Methods: We identified literature from inception to February 2016 reporting diabetes following exposure to oral GC in patients with PMR and/or GCA without preexisting diabetes. A random-effects meta-analysis was performed to summarise the literature. Risk of bias was assessed using the Cochrane Collaboration tool.

Results: 21 eligible publications were identified. In studies of patients with GCA, mean cumulative GC dose was almost two times higher than in studies of PMR $(8.9 \mathrm{~g}$ vs $5.0 \mathrm{~g}$ ), with slightly longer treatment duration but much longer duration of follow-up (8.8years vs 4.4 years). The incidence proportion (cumulative incidence) of patients who developed new-onset DM was 6\% (95\% Cl: 3-9\%) for PMR and $12 \%(95 \% \mathrm{Cl}: 8-17 \%)$ for GCA. Heterogeneity between studies was high $\left(I^{2}=78.2 \%\right)$, as there were differences in study designs, patient population, geographical locations and treatment strategies. Based on UK data on incidence rate of DM in the general population ${ }^{1}$, the expected background incidence rate of DM over 4.4 years in PMR patients and 8.8 years in GCA patients (the duration of follow-up) would be $4.8 \%$ and $9.7 \%$, respectively. Very little information on predictors of DM in PMR or GCA patients was found. The overall risk of bias was high for many of the observational studies, especially relating to definition and recording of outcome and prognostic variables.

$\begin{array}{lll}\text { Study Events Total } & \text { Proportion } & 95 \%-\mathrm{Cl} \text { W(random) }\end{array}$

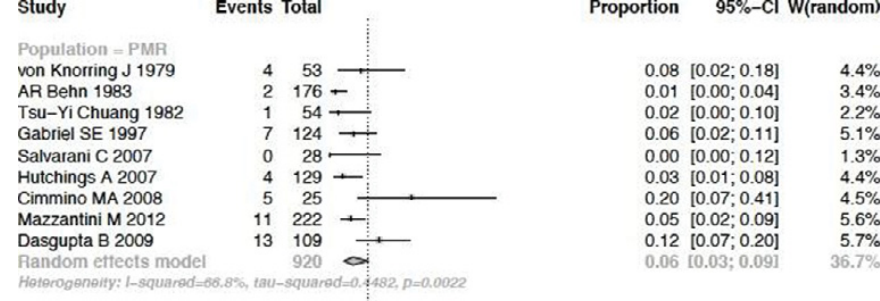

Population $=\mathrm{GCA}$

G Delecoeuillerie 19

Andersson R 1986

Gouet D 1985

Godeau P 1982

Nesher G 1994

Jover JA 2001

Proven A 2003

Schmidt WA 2008

Khalifa M 2009

Luciana ML 2011

Dunstan E 2013

Alba MA 2014

Fandom eftects model

Random effects mode

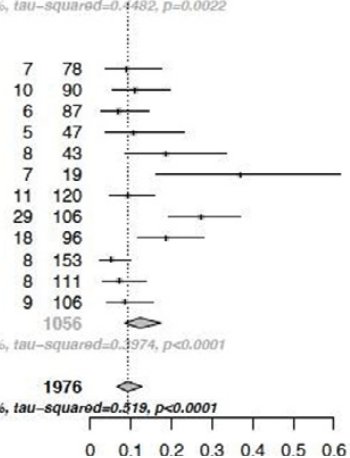

$0.09[0.04 ; 0.18]$

$0.11[0.05 ; 0.19]$

$0.07[0.03 ; 0.14$

$0.11[0.04 ; 0.23]$

$0.19[0.08 ; 0.33]$

$0.37[0.16 ; 0.62]$

$0.09[0.05 ; 0.16]$

$0.27[0.19 ; 0.37]$

$0.19[0.12 ; 0.28]$

$0.05[0.02 ; 0.10]$

$0.07[0.03 ; 0.14]$

$0.08[0.04 ; 0.16]$
$0.12[0.08 ; 0.17]$

$0.09[0.07 ; 0.13] \quad 100 \%$

$\begin{array}{lllllllll}0 & 0.1 & 0.2 & 0.3 & 0.4 & 0.5 & 0.6\end{array}$

$5.1 \%$

$5.5 \%$
$4.9 \%$

$4.6 \%$

$5.1 \%$
$4.6 \%$

$5.6 \%$

$5.1 \%$

$5.3 \%$

$5.3 \%$

$5.4 \%$

Conclusions: Physicians should screen patients treated for PMR/GCA for DM but it remains unclear what is the time-period of greatest risk and the influence of risk factors. Our meta-analysis produced plausible estimates of DM incidence in patients with PMR and GCA but there is insufficient published data to allow precise quantification of the DM risk or, crucially, which patients are at greatest risk.

\section{References:}

[1] Sharma M et al. BMJ Open, 2016. 6(1): p.e010210.

Disclosure of Interest: None declared

DOI: 10.1136/annrheumdis-2017-eular.4942 